\title{
Terceirização na administração pública
}

Tatiana Kian ${ }^{1}$

\section{Resumo}

\begin{abstract}
Delimita o momento histórico em que o instituto da terceirização foi implantado. Conceitua em sentido amplo, destacando sua aplicabilidade, nas esferas privada e pública. Aprofunda seu estudo no âmbito da Administração Pública, colocando-a como forma de aumentar a eficiência na prestação dos serviços públicos, com redução de custos. Alerta, no entanto, para os limites legais e aqueles estabelecidos por princípios de direito público, que devem ser observados na decisão do administrador em contratar terceiros para a consecução de atividades públicas. Define as regras dispostas na Lei de Responsabilidade Fiscal acerca do limite de gastos com despesas de pessoal, nos termos do art. 18, § 1‥ Conclui pela análise de todos os meios de que pode se valer o administrador para atingir o resultado que melhor atenda o interesse público, antes de adotar a terceirização indiscriminadamente, como solução imediata aos problemas administrativos.
\end{abstract}

Palavras Chave: Terceirização; Administração Pública.

\section{Introdução}

A expressão "terceirização", em sentido amplo, é a transferência de serviços para terceiros. Teve origem nos Estados Unidos, consolidando-se na década de 50, principalmente na indústria.

No Brasil, essa atividade teve início através das empresas multinacionais do setor automobilístico nas décadas de 50 e 60, impulsionada na década de 70, especialmente pela contratação de empresas de limpeza e conservação.

No setor público, historicamente, a tendência à terceirização surgiu em decorrência da Primeira Grande Guerra, que forçou o Estado a assumir a direção da economia através da correção dos desequilíbrios causados pelo conflito.

O chamado Estado de Bem-Estar social, assim, procurava conciliar o liberalismo e a socialização para garantir à sociedade condições de subsistência, admitindo a intervenção do Estado na ordem econômica e a propriedade privada dos meios de produção.

1 Especialista em Direito do Estado - Direito Administrativo pela Universidade Estadual de Londrina. 
Seu ápice ocorreu no período pós Segunda Guerra Mundial, quando o Estado aumentou sua atuação em diversas áreas, passando a prestar os serviços públicos diretamente ou através de entidades descentralizadas. Tal iniciativa, no entanto, tornou-se excessivamente onerosa aos cofres públicos, na medida em que os gastos com a manutenção do Estado Social eram maiores que a capacidade de custeio do sistema, obrigando o Estado à captação de recursos na própria sociedade.

Diante deste quadro, renasce a corrente neoliberal que, adaptada aos novos tempos, tem como premissa a liberdade do indivíduo e do mercado, tendo o Estado a função de regulação, para garantir a eficiência e a sobrevivência do mercado, corrigindo as distorções da economia capitalista.

Esta corrente prega, ainda, a descentralização, a privatização e a concentração dos programas sociais nos grupos mais carentes (focalização). A privatização, por seu turno, transfere para o setor privado a produção de bens e serviços públicos. Passa-se, portanto, do Estado mínimo para o Estado subsidiário, que tem como premissa, limitar e reduzir sua atuação, que ficaria restrita a atividades de auxílio, coordenação e fomento.

Essas são, resumidamente, as razões históricas que levaram ao processo de introdução da terceirização: de um lado, a crise do Estado Social de Direito, que se tornou caro e pouco eficiente no propósito de atender às necessidades coletivas, e de outro a internacionalização do processo produtivo, que obriga o Estado nacional, para manter competitiva a sua economia, a amoldar suas condições internas às expectativas dos capitais nacionais.

Assim, outras formas de participação da iniciativa privada passam a existir, como tendência crescente de substituição da execução direta de diversos serviços pela contratação de empresas privadas, substituindo o servidor público por terceiro contratado. O vocábulo terceirização, nesta senda, passa a ser incorporado à Administração Pública, constituindo, em princípio, vantagem para o tomador de serviços (no caso, o Estado), uma vez que se transfere a outrem o papel de empregador, permitindo o repasse da responsabilidade direta pelos encargos sociais.

Clara é a intenção do Estado, portanto, em reduzir o tamanho da máquina estatal e é diante deste quadro que a terceirização, sob a forma de contratos de obras e prestação de serviços, passou a ser uma das alternativas, junto à desregulação, à venda de ações de 
empresas estatais (desestatização), à concessão de serviços públicos, para a diminuição dos encargos antes reservados ao Estado.

O presente trabalho conceitua o instituto da terceirização, buscando aprofunda-lo através da exposição de seu funcionamento no setor privado para, em um segundo momento, definir sua implantação dentro da esfera da Administração Pública, suas bases jurídicas, com ênfase às dificuldades enfrentadas pelos administradores ao contratar serviços de terceiros, considerando a ausência de legislação específica, bem como pela confusão gerada com outros instrumentos de transferência de atividades do Estado para o setor privado, a exemplo da concessão de serviços públicos.

\section{Terceirização}

É uma forma de reorganização administrativa em que determinadas atividades de uma pessoa jurídica são transferidas para empresa contratada para essa finalidade. A terceirização é ainda chamada por alguns autores como subcontratação, focalização, descentralização, parceria, terciarização.

Dora Maria de Oliveira Ramos, citando Ciro Pereira da Silva, conceitua o instituto:

[...] transferência de atividades para fornecedores especializados, detentores de tecnologia própria e moderna, que tenham esta atividade terceirizada como sua atividade-fim, liberando a tomadora para concentrar seus esforços gerenciais em seu negócio principal, preservando e evoluindo em qualidade e produtividade, reduzindo custos e garantindo competitividade. (RAMOS, 2001, p.50)

\subsection{Terceirização no direito do trabalho}

O avanço tecnológico, aliado à globalização no mundo contemporâneo, fez com que o setor produtivo buscasse alternativas para o aperfeiçoamento dos bens e serviços produzidos, com redução de custos. Essa busca culminou em um processo de especialização cada vez maior, com a contratação de terceiros para as atividades que não constituíssem atividade principal.

Essa especialização passa a existir a partir do momento em que a empresa se focaliza para sua atividade principal, promovendo o aumento da produtividade, aperfeiçoamento do produto, bem como a já citada redução de custos, que pode se dar pela 
diminuição dos encargos e do espaço físico, por exemplo. O empresário reduz sua estrutura organizacional, sem restringir o âmbito de sua atuação.

A terceirização, assim, assume diversas formas, como a empreitada de obra e serviço, a locação de serviços ou fornecimento de mão-de-obra.

Com efeito, na empreitada o objeto contratual é a realização de determinada atividade pela empreiteira, visando ao fornecimento do objeto, que pode ser obra, serviço ou fornecimento de bens.

Por outro lado, o objeto da locação de serviços, é o fornecimento de mão-de-obra. Esta espécie de contrato, no entanto, apenas possui validade se ajustado nos moldes da Lei no 6.019/74, que trata do trabalho temporário, ou da Lei no 7.102/83, que dispõe sobre segurança para estabelecimentos financeiros, bem como normas para funcionamento de empresas que exploram serviços de vigilância.

Para dirimir quaisquer dúvidas a respeito do que seja terceirização lícita, o Tribunal Superior do Trabalho, em 17.12.93, editou o Enunciado no 331, que abrange também relações de terceirização no âmbito da Administração Pública:

I- A contratação de trabalhadores por empresa interposta é ilegal, formando-se vínculo diretamente com o tomador dos serviços, salvo no caso de trabalho temporário (Lei n. 6.019, de 3.1.74).

II- A contratação de trabalhador, através de empresa interposta, não gera vínculo de emprego com os órgãos da Administração Pública Direta, Indireta ou Fundacional (art. 37, II da Constituição da República).

III- Não forma vínculo de emprego com o tomador a contratação de serviços de vigilância (Lei n. 7.102, de 20.6.83), de conservação e limpeza, bem como a de serviços especializados ligados à atividade-meio do tomador, desde que inexistente a pessoalidade e a subordinação direta.

IV- O inadimplemento das obrigações trabalhistas, por parte do empregador, implica na responsabilidade subsidiária do tomador dos serviços quanto àquelas obrigações, inclusive quanto aos órgãos da administração direta, das autarquias, das fundações públicas, das empresas públicas e das sociedades de economia mista, desde que hajam participado da relação processual e constem também do título executivo judicial (artigo 71 da Lei n.8.666/93).

O item I do supracitado Enunciado não permite que situações tipificadoras de relação de emprego sejam consideradas legais, o que ocorre com os casos de utilização de formas contratuais admitidas pelo direito civil (empreitada ou prestação de serviços) que mascaram situações claras de relação de emprego intermediada por terceiros, onde o trabalho é o objeto contratual, sem que a ele estejam adicionados bens, produtos insumos 
ou serviços que exijam qualquer especialização (coloca-se apenas o trabalhador a disposição do tomador do serviço).

De outro turno, o item II do Enunciado prega a inexistência de vínculo com o Poder Público, com o intuito de coibir a prática de maus administradores que utilizam a terceirização para integrar apadrinhados aos quadros públicos, em detrimento da regra constitucional do art. 37, II - obrigatoriedade da realização de concurso público.

Entretanto, o não reconhecimento do vínculo de emprego com a Administração Pública, não significa que o gestor possa celebrar, sem sanções, contratações irregulares, na medida em que se assim agir, estará sujeito à disciplina da Lei de Improbidade Administrativa (Lei no 8.429/92), assim como ao ressarcimento dos prejuízos que venha a causar ao erário público.

O item III disciplina que não constitui relação empregatícia com o tomador a contratação de serviços de vigilância, de conservação e limpeza, assim como a de serviços especializados ligados à atividade-meio do tomador, desde que inexistente a pessoalidade e a subordinação direta.

Acerca do item IV do Enunciado, prevalece o entendimento de que a responsabilidade do tomador de serviço ocorre com o simples inadimplemento das obrigações trabalhistas pelo prestador do serviço, sem discussão da legalidade ou não da respectiva terceirização. Trata-se de responsabilização fundada na teoria do risco, pelo reconhecimento da culpa in eligendo e/ou in vigilando:

[...] mesmo não havendo relação de emprego entre o tomador de serviços e o empregado contratado por interposta pessoa, exatamente por esse fato é que o beneficiário da mão-de-obra responde subsidiariamente quanto às obrigações inadimplidas pelo real empregador, desde que participe da relação e conste do título (item IV do E. 331 do TST) .- TRT, 10a Região, 1a T., RO n.4964/97 - (CARRION, 1999, p.368).

Outro é o entendimento no sentido de que a responsabilidade do tomador só existirá caso se configure irregular intermediação de mão-de-obra. Tal corrente é minoritária e abraçada por doutrinadores como Amauri Mascaro Nascimento:

[...] a fraude é causa principal determinante da ilicitude da subcontratação. A responsabilidade subsidiária deve ser reconhecida como 'tecnica adequada nos 
casos em que a ilicitude da subcontratação for manifesta. (NASCIMENTO, 1998, p.380)

Referida corrente, considerando a aplicação para a Administração Pública, acertadamente coloca que o Estado responde apenas no caso de ações ou omissões praticadas pelo terceiro contratado, enquanto no exercício da execução do ajuste, nos termos do art. 37, § 60 da Constituição Federal, que trata da responsabilidade objetiva.

Saliente-se ainda que a responsabilização nestes casos é subsidiária, conforme letra expressa do Enunciado n. 331, ou seja, a obrigação apenas é transferida ao garante subsidiário se o devedor principal tornar-se inadimplente.

\section{Terceirização na administração pública}

A função administrativa, considerada em sua acepção objetiva (atividade de dirigir), pode ser realizada pelos Poderes Executivo, Legislativo e Judiciário, assim como por terceiros autorizados a atuar em nome do Estado, como se dá com os permissionários e concessionários de serviços públicos (RAMOS, 2001, p. 92).

Em resumo, é a junção das atividades de fomento, polícia administrativa, serviço público e intervenção.

Merece comentários a noção de serviço público como função administrativa do Estado, na medida em que o instituto da terceirização na Administração Pública é matéria a ser apreciada dentro deste conceito.

De acordo com Maria Sylvia Zanella Di Pietro (2004, p. 99), serviço público é toda atividade material que a lei atribui ao Poder público, para que diretamente, ou por meio de seus delegados, sejam satisfeitas necessidades de interesse público, sob regime jurídico total ou parcialmente público.

A prestação de serviços públicos é regida por princípios próprios, dentre eles, a igualdade dos usuários perante o serviço, a continuidade do serviço público, a mutabilidade do regime jurídico, a generalidade e a eficiência (DI PIETRO, 2004, p. 101).

Como a Administração Pública cada vez mais vêm transferindo à iniciativa privada a prestação de serviços públicos, o princípio da eficiência é um dos que devem ser especialmente observados. Referido princípio reza que o administrado não possui apenas o direito à prestação do serviço, mas à sua prestação satisfatória, célere e efetiva. 
Considerando o que foi até o momento exposto, indaga-se: de que critérios a Administração Pública pode se valer para decidir pela aplicação da terceirização?

Com efeito, devem ser analisados diversos fatores, principalmente se o serviço a ser prestado pelo terceiro irá atender satisfatoriamente a todos os princípios elencados acima. De outro turno, outros elementos, como o sigilo das informações, tornaria indesejada a rotatividade da mão-de-obra em determinado departamento.

Em síntese, se uma atividade exigir um detalhamento demasiado a ser observado pelo eventual contratado, o que causaria dificuldades para a fiscalização pela Administração Pública, deve se ponderar se este seria caso de terceirizar ou dar preferência à execução direta pelo Estado. Essa decisão é discricionária, onde deve prevalecer o bom-senso, ou seja, deve se decidir pela opção menos onerosa e mais eficiente ao atendimento do interesse público.

Outro critério a ser analisado para que determinado serviço público seja terceirizado é se ele pode ser delegado a outrem.

A partir daí, é possível identificar três espécies diversas de gestão dos serviços públicos: gestão estratégica, operacional e execução material.

A gestão estratégica refere-se à direção do serviço, bem como a delimitação de seu objetivo, tendo como titular, privativamente, o Poder Público. De outro turno, a gestão operacional envolve a concretização das diretrizes impostas pelo gestor estratégico, como ocorre, por exemplo, na criação de autarquias ou através de contratos com particulares (concessão ou permissão de serviços públicos).

A terceirização, nesta senda, enquadra-se no repasse da execução material do serviço ao particular.

A execução material do serviço público é a realização de atividades que não constituem serviço público em sua inteireza, eis que somente complementam o serviço, caracterizando-se ainda pela ausência de vínculo contratual entre o prestador do serviço e seu usuário. O terceiro, neste caso, não possui competência para gerir o serviço público, de vez que o executa em nome do gestor operacional, este com função reguladora e de otimização do serviço.

Os contratos de prestação de serviços terceirizados não entram nessa espécie de delegação de gestão operacional, uma vez que o contratado não possui poderes próprios de 
gestor do serviço público, limitando-se a prestar a atividade material em nome da Administração Pública, sob sua orientação.

Em sentido amplo, o que mais tem causado dúvidas a respeito da terceirização no âmbito da Administração Pública, é a representação de diversas formas de introdução do particular na prestação de serviços públicos. Assim, costuma-se chamar de terceirização qualquer serviço público prestado através de terceiro estranho aos quadros públicos, como a concessão de serviços públicos, por exemplo.

Em sentido restrito, na terceirização o gestor operacional apenas repassa, mediante contrato, a prestação de determinada atividade, para sua execução material. Não se trata, portanto de transferência de gestão de serviço público, mas de prestação de serviços.

O Decreto-Lei no 200/67, define que a execução material de atividades acessórias ao setor público, deve ser preferencialmente realizada através de contratação de terceiros. Essa também é a disciplina da Lei no 5.645/70, que estabelece que as atividades relacionadas com transporte, conservação, custódia, operação de elevadores, limpeza e outras semelhantes serão também, de preferência, objeto de execução indireta.

Posteriormente a Lei no 8.666/93 - Lei de Licitações e Contratos Administrativos elencou rol de contratação de serviços, tais como demolição, conserto, instalação, montagem, operação, conservação, reparação, adaptação, manutenção, transporte, locação de bens, publicidade, seguro ou trabalhos técnicos profissionais, nos moldes do art. 6으, II. Assim, referida Lei determina que a contratação desses serviços seja precedida de processo licitatório ou sua dispensa, nos termos legais, sob pena de nulidade.

Como se trata de rol exemplificativo, a Administração Pública cada vez mais tem se utilizado de contratos terceirizados para a execução de uma infinidade de atividades, como fornecimento de refeições, limpeza e vigilância, impressão gráfica, transporte, entre outros.

Entretanto, a multiplicação destes ajustes, acabaram envolvendo atividades que, ainda que acessórias, perdem o caráter próprio de especialização, lançando dúvidas sobre a legalidade na contratação. Exemplo bastante citado é o dos hospitais públicos que contratam cooperativas de médicos para prestarem serviços de suas especialidades profissionais, sem realização de concurso público para o provimento de seus cargos.

Considerando o que foi visto até o momento, pode se afirmar que há uma variedade de atividades que o Estado pode dirigir sem que as execute diretamente. 
Entretanto, nem todas as tarefas materiais acessórias podem ser terceirizadas, principalmente se na estrutura administrativa do Poder Público existirem cargos criados para atendimento àquelas necessidades .

Justifica-se tal entendimento pela relevância de certas atividades para o interesse da coletividade, devendo ser prestadas exclusivamente por servidores de carreira, na forma da lei.

Deste modo, a Administração Pública sofre limitações, tanto legais, quanto de outros princípios inerentes à atuação do Poder Público, como o princípio da eficiência, por exemplo.

Há que se agir com cautela nestes casos, uma vez que não é o fato de determinado serviço ser realizado mediante terceirização, que lhe confere maior eficiência.

Assim, a decisão pela terceirização deve se pautar por uma série de estudos, quanto à existência de cargos correspondentes às atividades que se pretenda terceirizar e que concluam que a execução por particulares é vantajosa ao interesse público.

\section{Terceirização e limite com despesas de pessoal}

A Lei Complementar no 101/2000 - Lei de Responsabilidade Fiscal - , que regulamentou o art. 169 da Constituição da República, impõe limite de gastos com pessoal na Administração Pública, com o objetivo de tentar conter artifícios que comprometam o equilíbrio das contas públicas.

Para tanto, foi determinada pela Lei a inclusão, no limite de gastos com despesas de pessoal, as contratações de serviços terceirizados. Observe:

Art. 18. Para os efeitos desta Lei Complementar, entende-se como despesa total com pessoal: o somatório dos gastos do ente da Federação com os ativos, os inativos e os pensionistas, relativos a mandatos eletivos, cargos, funções ou empregos, civis, militares e de membros de Poder, com quaisquer espécies remuneratórias, tais como vencimentos e vantagens, fixas e variáveis, subsídios, proventos da aposentadoria, reformas e pensões, inclusive adicionais, gratificações, horas extras e vantagens pessoais de qualquer natureza, bem como encargos sociais e contribuições recolhidas pelo ente às entidades de previdência. $\S 10$. Os valores dos contratos de terceirização de mão-de-obra que se referem à substituição de servidores e empregados públicos, serão contabilizados como 'Outras Despesas de Pessoal'. 
O art. 19 do diploma legal citado estabelece ainda que cada ente da Federação não poderá gastar com pessoal valores que superem $50 \%$ (cinqüenta por cento), para a União e $60 \%$ (sessenta por cento), no caso dos Estados e Municípios, da respectiva receita corrente líquida.

Desta forma, a decisão de contratar serviços terceirizados deve obediência ao artigo supracitado, ou seja, os contratos de terceirização de mão-de-obra, referentes à substituição de servidores serão incluídos no limite de gastos com pessoal.

Quando o artigo 18, § 1 da Lei de Responsabilidade Fiscal fala em "serviço", este deve ser interpretado em sentido amplo, ou seja, como atividade destinada a obter determinada utilidade de interesse para a Administração, nos moldes do art. 6으, II da Lei no 8.666/93.

Quais são, desta forma, os ajustes que representam substituição de servidores?

Conforme exposto anteriormente, a contratação de serviços de terceiros, é admissível para atividades auxiliares e complementares da administração pública, tendo como fundamento o artigo 10으, § 7음 do Decreto-lei no 200/67, assim como os artigos 6으, II; 10, II e 13 da Lei no 8.666/93, combinados com o artigo 3ㅇ da Lei no 5.645/70, que elenca alguns serviços tais como conservação, transporte, conservação dentre outros.

Nestes casos, os serviços a serem executados são complementares às atividadesfim, desde que não possuam correspondentes efetivos na estrutura de cargos e salários. Assim, uma vez não sendo considerados substituição a servidor público, não entrariam nos limites da Lei de Responsabilidade Fiscal.

Observe, nesta linha, o que estabelece o art. 61 da Lei 10.266/01, aplicável à União Federal, interpretando o art. 18, § 1ㅇ da LRF:

Art. 61. O disposto no $\S 1$ o do art. 18 da LC 101 de 2000, aplica-se exclusivamente para fins de cálculo do limite da despesa total com pessoal, independentemente da legalidade ou validade dos contratos.

Parágrafo único. Não se considera como substituição de servidores e empregados públicos, para efeito do caput, os contratos de terceirização relativos a execução indireta de atividades que, simultaneamente:

I. sejam acessórias, instrumentais ou complementares aos assuntos que constituem área de competência legal do órgão ou entidade, na forma do regulamento;

II. não sejam inerentes a categorias funcionais abrangidas por plano de cargos do quadro de pessoal do órgão ou entidade, salvo expressa disposição legal em contrário, ou quando se tratar de cargo ou categoria extinto, total ou parcialmente. III. não caracterizem relação direta de emprego 
Em suma, o intuito do legislador foi conter em parte as terceirizações realizadas pelo Poder Público com a função única e exclusiva de burlar a contabilização de despesas com pessoal no limite de gastos, para permitir apenas aquelas que efetivamente atendem ao interesse público.

Posto isto, é de ver-se que esse dispositivo, inserido como está na LRF, tem muito clara sua natureza jurídica de Direito Financeiro; quer isso significar que, nesse caso, a pretensão específica e exclusiva do legislador é evitar que, sob o rótulo da 'terceirização', sejam contabilizadas despesas tipicamente de pessoal, porque essenciais para o bom e próprio desenvolvimento do serviço, em rubrica diversa, como se fazia até então, burlando os limites impostos na lei. Isso e apenas isso; qualquer outra discussão reside ou na absoluta falta de trato com a ciência das finanças ou na deliberada tentativa de procurar 'chifre em cabeça de cavalo' (LINO, 2001, p. 83).

\section{Conclusão}

O trabalho realizado trouxe em linhas gerais o que se entende por terceirização, em vista das dificuldades do Poder Público em definir quais serviços podem ser objeto de contratação de terceiros. Isso se justifica pela própria deficiência legislativa acerca do assunto, que permite interpretações diversas.

O vocábulo "terceirização", muitas vezes é confundido com outras formas de intervenção do setor privado no âmbito da Administração Pública, como a concessão, ou permissão de serviços públicos. Ficou claro que a terceirização se perfaz através de contratos de prestação de serviços, precedida da respectiva realização de processo licitatório, ou sua dispensa, nos termos da Lei no 8.666/93.

Não existe, nesta senda, um instituto jurídico que possa ser denominado de terceirização, sendo que a expressão indica uma série de providências econômicas, que não apresentam conteúdo único ou específico. A terceirização pode efetivar-se por diversas modalidades, cada qual com perfil próprio. Mais ainda, a terceirização é uma alternativa de organização empresarial e não uma modalidade contratual específica.

A edição do Enunciado no 331 do TST, decidiu pela não configuração de vínculo de emprego com o Poder Público, em caso de contratações irregulares.

Também estabeleceu responsabilidade subsidiária do tomador do serviço em caso de inadimplemento de obrigações trabalhistas por parte do contratado. No entanto, no âmbito da Administração Pública, a posição dominante, da qual discordamos, é no sentido 
de que mesmo nos casos de regular contratação, subsiste a responsabilidade do tomador de serviços, em afronta ao art. 71, § 1ㅇ da Lei 8.666/93.

A Lei de Responsabilidade Fiscal também contribuiu para clarear a aplicação da terceirização, ao impor limites aos gastos com despesas de pessoal e estabelecendo quais são essas despesas, sendo que contratos de terceirização de mão-de-obra que correspondam a substituição de servidores e empregados públicos, entram neste limite.

Nota-se assim, diferenças substanciais entre a terceirização no setor público e privado, sendo que neste, os resultados são mais eficazes, principalmente por não esbarrar em limitações próprias do direito público (observância de princípios referentes aos serviços públicos, bem como da legislação vigente).

Existe ainda o descaso de certos administradores para com a essência do instituto da terceirização, mascarando verdadeira intermediação de mão-de-obra, ao contratar empresa interposta, o que tem gerado inúmeras ações no âmbito da Justiça do Trabalho.

Conclui-se, diante do exposto, que não se deve entender a terceirização como fórmula mágica que livraria a Administração Pública de todos os problemas administrativos, com a vantagem (ilusória) da redução de custos e responsabilidades.

Ao decidir pela contratação de terceiros, a Administração Pública deve analisar uma série de requisitos.

Pressupõe a inexistência no respectivo plano de cargos e salários da atividade que se pretenda terceirizar; que corresponda a atividades-meio, uma vez que é vedada a realização de contratos de prestação ou locação de serviço que tenha por objeto determinado serviço público como um todo.

Ademais, é imprescindível a análise discricionária da Administração Pública acerca da conveniência e oportunidade de determinada contratação. Muitas vezes, o que em princípio parece ser vantajoso do ponto de vista da redução de custos, não o é quando se pensa em eficiência no atendimento ao interesse público.

\section{Referências}

ARAÚJO, Luiz Alberto David; NUNES JUNIOR, Vidal Serrano. Curso de Direito Constitucional. 6. ed. São Paulo: Saraiva, 2002. 
CASTRO, Rubens Ferreira de. A terceirização do Direito do Trabalho. São Paulo: Malheiros, 2000.

DI PIETRO, Maria Sylvia Zanella. Parcerias na administração pública: concessão, permissão, franquia, terceirização e outras formas. 4. ed. São Paulo: Atlas, 2002.

. Direito Administrativo. 17. ed. São Paulo: Atlas. 2004.

JUSTEN FILHO, Marçal. Comentários à lei de licitações e contratos administrativos. 8. ed. São Paulo: Dialética, 2000.

LINO, Pedro.Comentários à lei de responsabilidade fiscal: lei complementar no 101/2000. São Paulo: Atlas, 2001.

MELLO, Celso Antônio Bandeira de. Curso de Direito Administrativo. 13. ed. São Paulo, 2001.

MOTTA, Carlos Coelho Pinto. Eficácia nas Licitações e Contratos. 9 ed. Belo Horizonte: Del Rey, 2002.

NASCIMENTO, Amauri Mascaro. Curso de direito do trabalho. 15. ed. São Paulo: Saraiva, 1998.

PEREIRA JUNIOR, Jessé Torres. Comentários à lei das licitações e contratações da administração pública. 6. ed. Rio de Janeiro: Renovar, 2003.

RAMOS, Dora Maria de Oliveira. Terceirização na administração pública. São Paulo: LTr, 2001.

SILVA, José Afonso da. Curso de Direito Constitucional Positivo. 19. ed. São Paulo: Malheiros, 2001.

TEIXEIRA JUNIOR, Amílcar Barca; CIOTTI, Lívio Rodrigues. Participação de Cooperativas em Procedimentos Licitatórios. Belo Horizonte: Mandamentos, 2002. 
Revista de Direito Público, Londrina, v. 1, N. 2, P. 227-240, MAio/Ago. 2006. 